of studies on discontinuation, dose reduction and/or spacing of bDMARDs have been performed, but there have been few reports on increased spacing time between tocilizumab (TCZ) administrations so far.

Objectives: To analyze the efficacy of spacing of the intravenous (IV) administration of TCZ in patients with RA.

Methods: 63 patients (11 M, 52 F) who were administered IV TCZ for more than 1 year were enrolled. Eleven patients had shifted to subcutaneous injection and the data at the last IV infusion were analyzed.

Results: Mean age was 57.4 years old (30-78), mean body weight was $55.5 \mathrm{~kg}$ (37-85.5), mean duration of illness was 10.7yrs (0-32), The number of the bDMARDs previously administered were $0.9(0-3)$, and duration of TCZ treatment was 46.9 months (13-83). The intervals between administrations were 4 weeks: $28.6 \%, 5$ weeks: $38.1 \%, 6$ weeks: $17.5 \%, 7$ weeks: $6.0 \%, 8$ weeks: $7.9 \%$, and 10 weeks: $1.6 \%$. Tender joint count, swollen joint count, erythrocyte sedimentation rate (ESR), C-reactive protein, matrix metalloproteinase-3 (MMP-3), patient's visual analogue scale (VAS), doctor's VAS, disease activity score (DAS) 28-ESR, simplified disease activity index (SDAI), clinical DAI (CDAI) were significantly improved. All of patients remission rates were $90.5 \%$ for DAS28-ESR, 44.4\% for $\mathrm{CDAl}$, and $42.9 \%$ for SDAI. Patients with prednisolone (PSL) decreased from 50 to $38(p=0.031)$, at doses of $5.3(2-10)$ to $2.7(0.5-5) \mathrm{mg} /$ day $(p<0.0001)$. Patients with methotrexate (MTX) decreased from 46 to 32 patients $(p=0.017$ ), at doses of $8.1(2-18)$ to $6.6(2-14) \mathrm{mg} /$ weeks $(p<0.0001)$. There were no changes in the usage of other csDMARDs. The remission rates of the patients with increased spacing $(n=45)$ were $75.6 \%$ for DAS28-ESR, $28.9 \%$ for CDAI, and $35.6 \%$ for SDAI. In 45 patients with increased spacing, both PSL and MTX were significantly reduced even after spacing (2.9: $0.5-5.5$ to $2.6: 1-7.0) \mathrm{mg} / \mathrm{day}$, and (6.45: $2-10$ to $5.2: 2-12) \mathrm{mg} /$ weeks, respectively ( $\mathrm{p}=0.0013, \mathrm{p}=0.0085)$. At the introduction of TCZ, there was no difference in the serum levels of MMP-3 in patients with increased spacing and without spacing $274.8(24-1310) \mathrm{ng} / \mathrm{ml}$ vs $283.3(32-626) \mathrm{ng} / \mathrm{ml} \mathrm{p}=0.692)$. Serum revels of MMP-3 at the first time of increased spacing were significantly lower in the patients with increased spacing than those at the final point of patients without spacing $72.0(22.2-236.0) \mathrm{ng} / \mathrm{ml}$ vs $165.8(35.8-619.0) \mathrm{ng} / \mathrm{ml}, \mathrm{p}=0.000752$. The number of patients with normal levels of MMP-3 among the patients with increased spacing were $25 / 45(55.6 \%)$ with significantly higher levels for those patients who had no spacing $3 / 18(16.7 \%$, $\mathrm{p}=0.00567$ ).

Conclusions: TCZ treatment was associated with significantly reduced disease activity and reduced use of PSL and MTX. Increased spacing between administrations was used in $71.4 \%$ of the patients. TCZ was able to reduce PSL and MTX even after spacing. MMP-3 might be a useful marker to decide the spacing period. TCZ is the most inexpensive bDMARD in Japan, but with increased spacing, it is possible to reduce the cost even further with acceptable control of RA symptoms. Disclosure of Interest: None declared

DOI: 10.1136/annrheumdis-2017-eular.2335

\section{SAT0215 CHARACTERISTICS OF PATIENTS WITH ANKYLOSING SPONDYLITIS, RHEUMATOID AND PSORIATIC ARTHRITIS IN TREATMENT WITH BIOLOGICS IN VERONA'S COHORT: RESULTS FROM VENETO'S REGION BIOLOGICS REGISTER}

S. Troplini, O. Viapiana, E. Fracassi, A. Carletto, L. Idolazzi, G. Orsolini, A. Giollo, M. Rossini. Rheumatology Unit, University of Verona, Verona, Italy

Background: Since 2013, in Veneto's Region, data registration is mandatory for all patients affected by Rheumatoid arthritis (RA), Psoriatic Arthritis (PA), Ankylosing Spondylitis (AS) in treatment with biologic agents. The biologic DMARDs currently marketed in Italy are: anti-TNF (originator and biosimilar infliximab, etanercept, adalimumab, certolizumab and golimumab), anti-IL6 (tocilizumab), anti-CD20 (rituximab), CTLA-4 like (abatacept) and anti IL-12/23 (ustekinumab).

Objectives: The aim of this study was first to describe the characteristics of patients with RA, PA, AS under biologics and then, to extract and analyze real-life data regarding rheumatic treatments in Verona's cohort.

Methods: The study has been carried out on behalf of Regione del Veneto, Giunta regionale- Ricerca Sanitaria Finalizzata-Venezia-Italy. Data used for analysis were retrieved from Veneto's Region Biologics Register (VRBR). VRBR provides that core variables such as onset and type of disease, anthropometric characteristics (age, sex, body weight, height) are registered at the beginning. Furthermore, prior and concomitant rheumatic treatment (conventional and biologic DMARDs, corticosteroids, NSAIDs), disease activity indicators (DAS 28-PCR, ASDAS-PCR, pain-NRS), prognostic factors (positivity for rheumatoid factor and/ or anti-citrulline antibodies in AR, presence of radiological erosions) were assembled at baseline, every 6 months and at the time of biologic's switch or swap.

Results: A total of 983 patients under biologics were examined; $543(55,2 \%)$ with AR, $272(27,7 \%)$ with AP and $168(17,1 \%)$. Between these, $262(27,2 \%)$ patients were naïve to biologics, 128 with AR, 84 with AP, 50 with SA. Mean duration of disease was of $15,3,10,7$ and 12,6 years respectively for RA, PA and AS. Radiological erosions were present in $73 \%$ of RA-patients and the percentage was higher in those with positivity for rheumatoid factor and/ or anti-citrulline antibodies ( $84,4 \%$ versus $56,2 \%$ ). More than half of the patients in this cohort were treated at least with one biologic agent; anti-TNFs were the main biologic used (RA:54,8\%, PA:92,7\%, AS: $100 \%)$ followed by Abatacept $(25,4 \%)$, tocilizumab $(12,3 \%)$ and rituximab $(5,9 \%)$ in patients with RA. Methotrexate (MTX) was the prevalent associated c-DMARDs $(41,8 \%$ in RA and $34,2 \%$ in PA) with mean dose of $11,9 \mathrm{mg} /$ week in RA and $12,1 \mathrm{mg} /$ week in PA. The optimal dose of methotrexate was not achieved prevalently because of drug intolerance.

Conclusions: Profile of both conventional and biological DMARDs looks very different according to the type of rheumatic disease. The first data show an underuse of MTX in patients with RA and PA under biologics with a low mean dosage due to intolerance. Next step is to evaluate long-term outcomes in clinical practice.

Disclosure of Interest: None declared

DOI: 10.1136/annrheumdis-2017-eular.5718

\section{SAT0216 ABATACEPT EXPERIENCE IN BIOLOGIC NAIVE RHEUMATOID ARTHRITIS PATIENTS: HUR-BIO REAL LIFE RESULTS}

A. Sari, B. Armagan, L. Kilic, A. Erden, O. Karadag, A. Akdogan, S. Apras Bilgen, S. Kiraz, U. Kalyoncu, I. Ertenli. Rheumatology, Hacettepe University School of Medicine, Ankara, Turkey

Background: Abatacept (ABA), a T lymphocyte blocker, is one of the treatment options in rheumatoid arthritis (RA) patients who are resistant to initial therapy with non-biologic disease modifying drugs (DMARDs).

Objectives: Aim of this study was to evaluate the effectiveness, safety and drug survival rates of ABA in RA patients registered in HUR-BIO (Hacettepe University Rheumatology Biologic Registry) database.

Methods: HUR-BIO is a prospective, single center database of biological treatments including 1229 RA patients by August 2016. In total, 247 of patients had received $\mathrm{ABA}$ and in $175(71 \%)$ of them $\mathrm{ABA}$ was the first biological agent. In this analysis, 158 patients were evaluated due to lack of first follow-up visit in 17 patients. Demographics, clinical and serological data were evaluated. DAS-28 and $H A Q-D I$ scores before $A B A$ and last follow-up visit were also assesed. Kaplan-Meier analysis was used to estimate drug survival rates.

Results: Among 175 (82\% female) patients, mean age was $53.6 \pm 11.3$ and mean disease duration was $10.3 \pm 7.3$. Seropositivity for RF and/or ACPA was present in $74.8 \%$ of patients. Table 1 represents DAS- 28 scores of patients before ABA and last follow-up visit. Mean duration from ABA initation to first and last follow-up visit was $4.5 \pm 3.1$ and $15.1 \pm 10.2$ months, respectively. Female gender was found as a risk factor in terms of remaining of DAS-28 above 3.2 at first control [OR 5,63 (\%95 Cl 1,72-18,41)]. In first follow-up visit, improvement in DAS-28 score of $\geq 1,2$ from baseline was more frequent in ACPA positive patients (48/62 $(77.4 \%)$ vs $17 / 33$ (51.5\%), $p=0.01)$. HAQ score of $>1.0$ was observed in $57.8 \%, 36.3 \%$ and $26.1 \%$ of patients at baseline, first follow-up visit and last follow-up visit, respectively. ABA had been cessated in $60(38.0 \%)$ patients during follow-up. The reason for ABA withdrawal was primary unresponsiveness in $22(36.6 \%)$ patients and infection in $2(3.3 \%)$ patients. Drug survival for ABA was shown in Figure 1. Logrank between RF positive and negative patients was found as 0.067 .

Table 1. DAS-28 scores at first and last follow-up visits

\begin{tabular}{lcc}
\hline & $\begin{array}{c}\text { First control visit } \\
(\mathrm{n}=136)\end{array}$ & $\begin{array}{c}\text { Last control visit } \\
(\mathrm{n}=136)\end{array}$ \\
\hline Follow up duration, mean (SD) & $4.5(3.1)$ & $12,3(10.9)$ \\
DAS-28 $>5.1, \mathrm{n}(\%)$ & $11(8.2)$ & $16(11.8)$ \\
DAS-28 $=3.2-5.1, \mathrm{n}(\%)$ & $56(41.8)$ & $46(33.8)$ \\
DAS-28=2.6-3.2, $(\%)$ & $23(17.2)$ & $23(16.9)$ \\
DAS-28 $<2.6, \mathrm{n}(\%)$ & $44(32.8)$ & $51(37.5)$ \\
$\begin{array}{l}\text { Remission or low disease activity among patients } \\
\quad \text { with at least one follow-up visit, } \mathrm{n}(\%)\end{array}$ & $67(50.0)$ & $74(54.4)$ \\
$\begin{array}{l}\text { Remission or low disease activity among all patients, } \\
\quad \mathrm{n}(\%) \text { (The worst scenario) }\end{array}$ & $67 / 158(42.4)$ & $74 / 158(46.8)$ \\
\hline
\end{tabular}

Figure 1. ABA survival rates in RF positive and negative patients

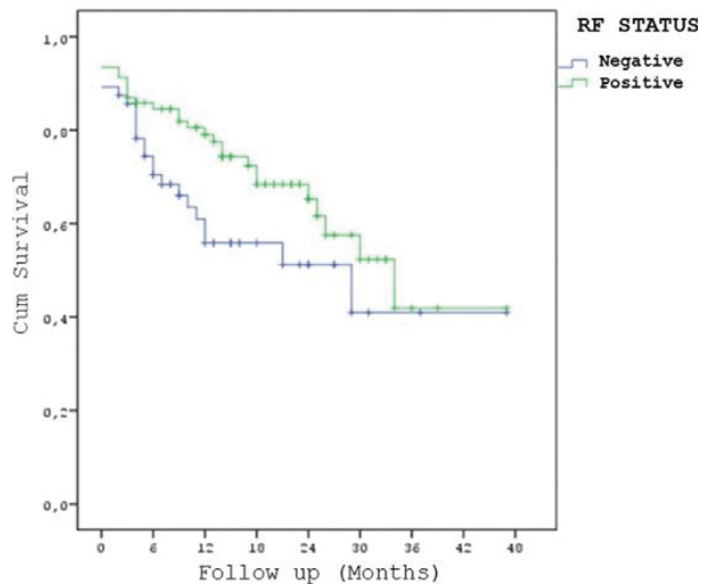

Conclusions: In our database, $70 \%$ of RA patients received $A B A$ were biologic naive. Remission or low-disease activity was achieved approximately $50 \%$ of patients in first follow-up visit with an average of 4.5 months after begining of the treatment. Functional improvement was observed in two thirds of patients. 
Death or life threatening side effects were not seen during follow-up. ABA is an acceptable treatment option in DMARD resistant biologic naive RA patients. Disclosure of Interest: None declared

DOI: 10.1136/annrheumdis-2017-eular.4082

\section{SAT0217 EARLY PATIENT-REPORTED OUTCOMES AND CLINICAL OUTCOMES WITH ABT-494 IN PATIENTS WITH ACTIVE RHEUMATOID ARTHRITIS WHO ARE INADEQUATE RESPONDERS TO METHOTREXATE OR TUMOR NECROSIS FACTOR INHIBITORS: POST-HOC ANALYSIS OF PHASE 2 RANDOMIZED CONTROLLED TRIALS}

V. Strand ${ }^{1}$, N. Tundia ${ }^{2}$, I.H. Song ${ }^{2}$, S. Meerwein ${ }^{2}$, J. Lin ${ }^{2}$, N. Chen ${ }^{2}$, A. Friedman ${ }^{2} .{ }^{1}$ Stanford University, Palo Alto; ${ }^{2}$ AbbVie Inc., North Chicago, United States

Background: Janus kinase (JAK) inhibitors are being evaluated for treatment of active rheumatoid arthritis (RA). Understanding their onset of action on patient reported outcomes (PROs) and clinical endpoints in RA patients (pts) is limited. Objectives: To assess onset of benefit with ABT-494, a selective JAK1 inhibitor vs placebo (PBO) in RA pts with active disease $>3$ months in 2 randomized controlled trials (RCTs) evaluating safety and efficacy of ABT-494. M13-537 (NCT02066389) included pts who were inadequate responders to methotrexate (MTX-IR) and M13-550 (NCT01960855) to tumor necrosis factor inhibitors (TNF-IR).

Methods: Data were analyzed separately for each RCT in pts who received $6 \mathrm{mg}$ or $12 \mathrm{mg}$ bid ABT-494 or PBO. Analyses included cumulative assessment of PROs such as patient global assessment of disease activity (PtGA), pain Visual Analogue Scale (VAS) and Health Assessment Questionnaire Disability Index (HAQ-DI) in terms of Routine Assessment of Patient Index Data 3 (RAPID3) scores, and clinical outcomes such as DAS28 (CRP) and CDAl. To assess onset and maintenance of effect, the number of pts whose improvements met or exceeded minimal important differences (MID) RAPID3: reduction $\geq 3.6$; DAS28: reduction $\geq 1.2$; CDAl: reduction $\geq 11.0$ and were calculated at weeks 2 and 12 . Additionally, Kaplan-Meier (KM) analysis estimated mean time to achievement of RAPID3, DAS28 and CDAI MID. Non-responder imputation accounted for missing data.

Results: In M13-537 (N=150 pts) and M13-550 (N=166 pts) RCTs, significantly more pts in ABT-494 12mg groups reported improvements $>$ MID in RAPID3 vs PBO at Wk 2: $68 \%$ vs $30 \%$ and $73 \%$ vs $38 \%$, respectively (Table). In M13-537, significantly more pts receiving ABT-494 $6 \mathrm{mg}$ BID vs PBO (54\% vs $30 \%)$ had improvements $>$ MID in RAPID3. These responses were sustained throughout both trials in pts receiving 12mg ABT-494 (M13-537: 80\%; M13-550: 71\%). Significantly more pts achieved and maintained changes $\geq$ MID in DAS28 in both RCTs and in CDAl in M13-550. Based on KM analyses, in M13-537, estimated mean time ( \pm SE) to achievement of RAPID3 MID was shorter for both ABT-494 doses vs PBO (12mg: $3.9 \pm 0.5$ weeks; $6 \mathrm{mg}: 3.9 \pm 0.4$ weeks; PBO $6.0 \pm 0.6$ weeks). Similarly, estimated mean time to these responses was shorter with both ABT-494 doses vs PBO (12mg: $3.6 \pm 0.4$ weeks; $6 \mathrm{mg}: 4.9 \pm 0.6$ weeks; PBO: $6.6 \pm 0.6$ weeks) in M13-550, although it was underestimated due to censoring.

\begin{tabular}{|c|c|c|c|c|c|c|}
\hline \multirow[b]{2}{*}{$n(\%)$} & \multicolumn{3}{|c|}{ M13-537 } & \multicolumn{3}{|c|}{ M13-550 } \\
\hline & $\begin{array}{c}\text { ABT-494 6mg } \\
N=50\end{array}$ & $\begin{array}{c}A B T-49412 \mathrm{mg} \\
\mathrm{N}=50\end{array}$ & $\begin{array}{l}\text { PBO } \\
\mathrm{N}=50\end{array}$ & $\begin{array}{c}\text { ABT-494 6mg } \\
N=55\end{array}$ & $\begin{array}{c}\text { ABT- } 49412 \mathrm{mg} \\
\mathrm{N}=55\end{array}$ & $\begin{array}{l}\text { PBO } \\
\mathrm{N}=56\end{array}$ \\
\hline \multicolumn{7}{|c|}{ RAPID3: 2MID } \\
\hline Week 2 & $27(54)^{0}$ & $34(68)^{b}$ & $15(30)$ & $25(45)$ & $40(73)^{\mathrm{b}}$ & $21(38)$ \\
\hline Week 12 & $32(64)$ & $40(80)^{b}$ & $24(48)$ & $35(64)^{a}$ & $39(71)^{b}$ & $23(41)$ \\
\hline \multicolumn{7}{|c|}{ DAS28: $\geq$ MID } \\
\hline Week 2 & $26(52)^{\circ}$ & $27(54)^{b}$ & $9(18)$ & $27(49)^{\circ}$ & $36(65)^{b}$ & $14(25)$ \\
\hline Week 12 & $37(74)^{\circ}$ & $44(88)^{\mathrm{b}}$ & $22(44)$ & $32(58)$ & $38(69)^{\mathrm{b}}$ & $23(41)$ \\
\hline \multicolumn{7}{|c|}{ CDAI: $\geq M I D$} \\
\hline Week 2 & $25(50)$ & $25(50)$ & $17(34)$ & $33(60)^{\circ}$ & $33(60)^{\mathrm{b}}$ & $21(38)$ \\
\hline Week 12 & $36(72)^{\circ}$ & $42(84)^{b}$ & $26(52)$ & $39(71)$ & $42(76)^{b}$ & $29(52)$ \\
\hline
\end{tabular}

Conclusions: Patients treated with ABT-494 showed fast clinically meaningful improvements in patient reported disease activity, pain, physical function cumulatively assessed as RAPID3, as well as clinical outcomes DAS28 and CDAI, as early as week 2 and sustained through week 12 in both MTX-IR and TNF-IR populations.

Acknowledgements: Financial support for the study and medical writing support (Joann Hettasch, Fishawack Group, Conshohocken, PA) was provided by AbbVie. AbbVie participated in interpretation of data, review, and approval of the abstract. All authors contributed to development of the abstract and maintained control over final content.

Disclosure of Interest: V. Strand Consultant for: AbbVie, Amgen, AstraZeneca, BMS, Celgene, Genentech, GSK, Janssen, Lilly, Novartis, Pfizer, Regeneron, Sanofi, and UCB; Ad boards: AbbVie, Amgen, AstraZeneca, BMS, Celgene, Genentech, GSK, Janssen, Lilly, Novartis, Pfizer, Regeneron, Sanofi, and UCB, N. Tundia Shareholder of: AbbVie, Employee of: AbbVie, I. H. Song Shareholder of: AbbVie, Employee of: AbbVie, S. Meerwein Shareholder of: AbbVie, Employee of: AbbVie, J. Lin Shareholder of: AbbVie, Employee of: AbbVie, N. Chen Shareholder of: AbbVie, Employee of: AbbVie, A. Friedman Shareholder of: AbbVie, Employee of: AbbVie
DOI: 10.1136/annrheumdis-2017-eular.1143

\section{SAT0218 EFFECT OF TOCILIZUMAB IN DMARD-NAÏVE EARLY RHEUMATOID ARTHRITIS PATIENTS ON HEALTH-RELATED QUALITY OF LIFE: RESULTS OF THE U-ACT-EARLY TRIAL}

X.M. Teitsma ${ }^{1}$, J.W. Jacobs ${ }^{2}$, P.M. Welsing ${ }^{2}$, A. Pethö-Schramm ${ }^{3}$, M.E. Borm ${ }^{4}$ J.M. van Laar ${ }^{1}$, F.P. Lafeber ${ }^{1}$, J.W. Bijlsma ${ }^{1},{ }^{1}$ Rheumatology and Clinical Immunology; ${ }^{2}$ UMC Utrecht, Utrecht, Netherlands; ${ }^{3} \mathrm{~F}$. Hoffmann-La Roche, Basel, Switzerland; ${ }^{4}$ Roche Nederland B.V., Woerden, Netherlands

Background: Tocilizumab (TCZ), a humanized interleukin-6 receptor inhibitor, has been shown effective in suppressing symptoms of rheumatoid arthritis (RA). In U-Act-Early, a significantly greater proportion of patients with early RA who initiated TCZ (84\%) or TCZ plus MTX therapy (86\%) achieved sustained remission (Disease Activity Score assessing 28 joints (DAS28) $<2.6$ with $\leq 4$ swollen joints for $\geq 24$ weeks), when compared to those initiating MTX (44\%). [1]

Objectives: To determine the effect of treat-to-target TCZ therapy, with or without MTX, on health-related quality of life (HRQoL) in disease modifying anti-rheumatic drugs (DMARD)-naïve patients with early RA.

Methods: Patients $(n=317)$ were randomized to initiate TZC, TCZ+MTX or MTX therapy and treated according to a step-up strategy. TCZ was given $(8 \mathrm{mg} / \mathrm{kg})$ every 4 weeks and MTX (oral) was started at $10 \mathrm{mg} /$ week and increased with steps of $5 \mathrm{mg}$ steps 4 weekly up to $30 \mathrm{mg} /$ week (or maximum tolerable dose) until remission. If after 20 weeks remission was not achieved, hydroxychloroquine was added and discontinued 12 weeks thereafter if the target still was not achieved. Patients who originally initiated monotherapy then switched to TCZ+MTX therapy and those already on this combination therapy switched to a tumour necrosis factor inhibitor. To evaluate the effect of TCZ on HRQoL, we used the 36-item Short-Form (SF-36), which can be summarized into a physical (PCS) and mental (MCS) component score. HRQoL was measured at baseline and after 12, 24, 52, and 104 weeks. A linear mixed effect model with a random intercept was used to evaluate differences between treatment strategies over time with visit (time), strategy, baseline SF-36 score, baseline DAS28 level (i.e., DAS28 $<5.1$ or $\geq 5.1$ ) and centre as fixed effects. The proportions of patients exceeding the minimum clinically important differences (MCID, $\geq 2.5$-point increase from baseline) were tested for significance using the two-sided Pearson's chi-squared test.

Results: We found significantly greater improvements over time in the SF-36 PCS in patients initiating treatment with TCZ (TCZ vs MTX; $\mathrm{p}=0.041, \mathrm{TCZ}+\mathrm{MTX}$ vs MTX; $p=0.011$, Fig. 1). For the SF-36 MCS, no significant differences over time were noted between the treatment arms $(p>0.11)$. A significantly higher proportion of patients initiating treatment with TCZ $(76 \% ; p=0.016,89 \% ; p=0.030)$ or TCZ+MTX (73\%; $p=0.049,89 \% ; p=0.027)$ achieved MCID in the SF-36 PCS at week 12 and week 52, when compared to those initiating treatment with MTX (59\% and $73 \%$, respectively). Although the proportions of patients achieving MCID in the SF-36 MCS were numerically higher in the TCZ arms, no significant differences were found $(p \geq 0.06)$.

Fig. 1: Mean (SE) change from baseline in SF-36 PCS (A) and SF-36 MCS (B)
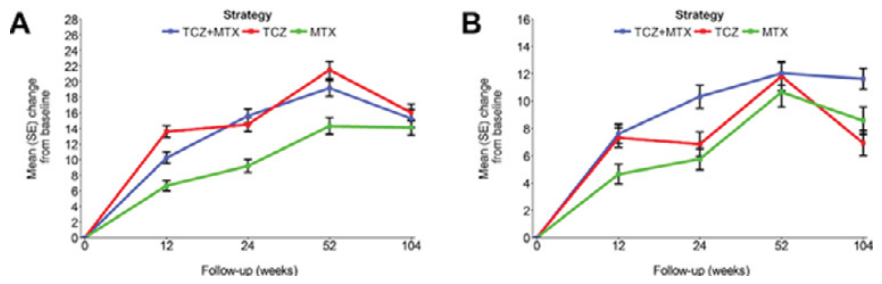

Conclusions: Initiation of TCZ, with or without MTX, at start of therapy resulted in statistically significant and clinically relevant improvements in the HRQoL when compared to initiation of MTX alone and may be considered as a valuable treatment strategy in DMARD-naïve patients with early RA.

\section{References:}

[1] Bijlsma JW, Welsing PM, Woodworth TG, et al. Early rheumatoid arthritis treated with tocilizumab, methotrexate, or their combination (U-Act-Early): a multicentre, randomised, double-blind, double-dummy, strategy trial. Lancet 2016; 388:343-55

Disclosure of Interest: X. Teitsma: None declared, J. Jacobs: None declared, P. Welsing: None declared, A. Pethö-Schramm Employee of: Employee of F.Hoffmann-La Roche, M. Borm Employee of: Roche Nederland B.V., J. van Laar Consultant for: Received fees from MSD, Pfizer, Roche, Eli Lilly and BMS, F. Lafeber: None declared, J. Bijlsma Grant/research support from: Received research grants (to his department) and consultancy fees from AbbVie, BMS, Crescendo, MSD, Mundipharma, Pfizer, Roche, Sun and UCB

DOI: 10.1136/annrheumdis-2017-eular.2190 